\section{Commentary: Fontan circulation, pulmonary blood flow, and lessons from the FUEL (Fontan Udenafil Exercise Longitudinal) study}

John M. Karamichalis, MD

Although advances in the surgical management of univentricular congenital heart disease have come a long way, ${ }^{1,2}$ the final physiology achieved by the Fontan procedure suffers from physiologic flaws: central venous pressure is chronically elevated whereas cardiac output is chronically diminished. ${ }^{3}$ Manipulating the Fontan circuit is extremely challenging to overcome the solution provided by millions of years of evolution: a subpulmonary ventricle. The Achilles' heel of the Fontan physiology is preload deprivation, and not systolic ventricular failure, ${ }^{4,5}$ emphasizing the importance of carefully preparing the most limiting building block of such a circuit: the pulmonary vasculature and its optimization.

In the manuscript by Rychick ${ }^{6}$ in the current issue of the Journal, the author critically appraises the complexity of the determinants of pulmonary blood flow. Understanding the factors that influence pulmonary blood flow in the absence of a subpulmonary ventricle is crucial. More importantly, comprehending the magnitude of contribution of each of these variables in driving blood forward becomes critical in designing further practical experimentation to solve unanswered questions, modify conditions, and create a more favorable Fontan circuit.

The role of pulmonary vascular resistance as a modulator of pulmonary blood flow and single-ventricular preload cannot be stressed more and it becomes critical to circulatory

\footnotetext{
From the Division of Cardiac, Thoracic and Vascular Surgery, New York-Presbyterian/Morgan Stanley Children's Hospital-Columbia/Komansky Weill-Cornell, New York, NY.

Disclosures: The author reported no conflicts of interest.

The Journal policy requires editors and reviewers to disclose conflicts of interest and to decline handling or reviewing manuscripts for which they may have a conflict of interest. The editors and reviewers of this article have no conflicts of interest.

Received for publication Nov 23, 2020; revisions received Nov 23, 2020; accepted for publication Nov 23, 2020; available ahead of print Dec 3, 2020.

Address for reprints: John M. Karamichalis, MD, Division of Cardiac, Thoracic and Vascular Surgery, New York-Presbyterian/Morgan Stanley Children's HospitalColumbia/Komansky Weill-Cornell, 3959 Broadway, CHN-274, New York, NY 10032 (E-mail: jkaramichalis@yahoo.com).

J Thorac Cardiovasc Surg 2021;162:1239-40

$0022-5223 / \$ 36.00$

Copyright (C) 2020 by The American Association for Thoracic Surgery

https://doi.org/10.1016/j.jtcvs.2020.11.121
}

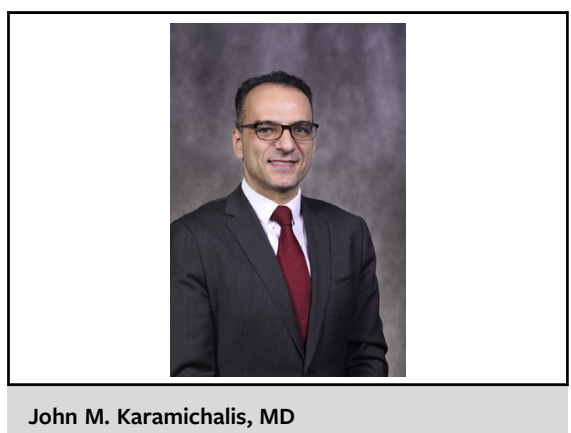

CENTRAL MESSAGE

Understanding the complexity and the magnitude of contribution of the determinants of pulmonary blood flow in Fontan circuit is crucial in designing further practical experimentation.

efficiency. ${ }^{3,4}$ The efficiency of the architecture of systemic venous connections to the pulmonary arteries, streamlining of the flow, the downstream diastolic properties of the systemic ventricle, the active mechanics of ventricular contraction during systole, and peripheral musculature, are other important pulmonary blood flow determinants. ${ }^{6}$

The FUEL (Fontan Udenafil Exercise Longitudinal) trial $^{3}$ is the first large-scale, multi-institutional, placebocontrolled, randomized trial to examine the effects of a specific pulmonary vasodilator udenafil in medically optimizing the Fontan circulation, and specifically its effects on exercise performance for adolescent patients.

This is the largest clinical trial of its kind, and the significance of this achievement cannot be overstated. ${ }^{5,6}$ Disappointingly, the primary end point of peak exercise capacity as measured by peak oxygen consumption did not significantly improve; however, measures of submaximal exercise showed a small but significant improvement.

However, the important lesson to learn from this key trial relates to the complexity of determinants of pulmonary blood flow in the Fontan circulation. ${ }^{6}$ Pulmonary vasodilation may not be a major determinant of pulmonary blood flow, and other factors will need to be studied using the same methodology used in FUEL.

Although essentially a negative study, the FUEL trial serves as a gold standard that provides invaluable information for how to design a study to advance knowledge and 
further research. ${ }^{5,6}$ Although the wisdom of Diogenes Solvitur ambulando, or the problem is solved by practical experimentation, is relevant today, perhaps equally important is to apply "scientific methodology" first introduced by Aristotle, another ancient Greek philosopher (384-322 BC). Well-designed, multicenter, randomized, double-blind, and controlled studies examining the determinants of pulmonary blood flow and their effect in optimizing Fontan circulation will afford the medical community the benefit of pushing the frontiers in this field with great benefits for these patients.

\section{References}

1. Fontan F, Baudet E. Surgical repair of tricuspid atresia. Thorax. 1971;26: 240-8.

2. Rodefeld MD, Masden A, Figliola R, Jonas T, Neary M, Giridharan GA. Cardiopulmonary assist: long-term reversal of the Fontan paradox. J Thorac Cardiovasc Surg. 2019;158:1627-36.

3. Goldberg DJ, Zak V, Goldstein BH, Schumacher KR, Rhodes J, Penny DJ, et al. Results of the FUEL trial. Circulation. 2020;141:641-51.

4. Gewilling M, Goldberg DJ. Failure of the Fontan circulation. Heart Fail Clin. 2014; 10:105-16.

5. Gewillig M, van de Bruaene A. FUELing the search for medical therapies in late Fontan failure. Circulation. 2020;141:652-4.

6. Rychik J. What "FUEL"s the Fontan circulation-Solvitur ambulando! J Thorac Cardiovasc Surg. 2021;162:1234-8.

\section{See Article page 1234 .}

\section{Commentary: It's the engine, not the fuel}

\section{Carl L. Backer, MD}

Rychik $^{1}$ has provided an insightful analysis of the somewhat disappointing results from the very well-conducted Fontan Udenafil Exercise Longitudinal (FUEL) study. He acknowledges this study to be a true tour de force, with hundreds of patients enrolled across multiple institutions; the largest clinical trial of its kind ever undertaken in congenital heart care. Part of the disappointment of this trial is that health care providers managing the care of Fontan patients are clearly hungry to discover and employ new, effective strategies to improve the quality of life of these patients. Rychik $^{1}$ notes that although treatment with udenafil was not associated with an improvement in oxygen consumption at peak exercise, there was some improvement in exercise performance at submaximal activities like walking. This activity may actually be more important than the findings at peak exercise and probably merits further investigation.

From the Section of Pediatric Cardiothoracic Surgery, UK HealthCare Kentucky Children's Hospital, Lexington, Ky; and Department of Cardiothoracic Surgery, Heart Institute, Cincinnati Children's Hospital Medical Center, Cincinnati, Ohio. Disclosures: Dr Backer is a consultant to W.L. Gore \& Associates.

The Journal policy requires editors and reviewers to disclose conflicts of interest and to decline handling or reviewing manuscripts for which they may have a conflict of interest. The editors and reviewers of this article have no conflicts of interest.

Received for publication Sept 24, 2020; revisions received Sept 24, 2020; accepted for publication Sept 25, 2020; available ahead of print Oct 5, 2020.

Address for reprints: Carl L. Backer, MD, Section of Pediatric Cardiothoracic Surgery, UK HealthCare Kentucky Children's Hospital, 800 Rose St, C-259, Lexington, KY 40536-0293 (E-mail: carl.backer@uky.edu).

J Thorac Cardiovasc Surg 2021;162:1240-1

$0022-5223 / \$ 36.00$

Copyright $₫ 2020$ Published by Elsevier Inc. on behalf of The American Association for Thoracic Surgery

https://doi.org/10.1016/j.jtcvs.2020.09.112
Check for updates

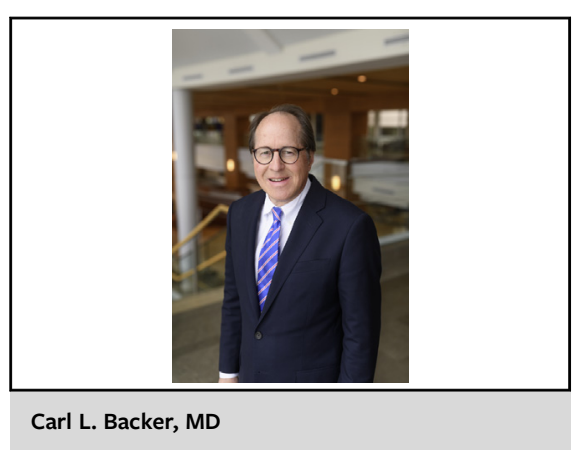

CENTRAL MESSAGE

Decreasing pulmonary vascular resistance may provide marginal improvement for Fontan patients, but it is the strength of the engine in the circulation that is the most important factor for determining pulmonary blood flow.

In addition to pulmonary vasoreactivity, I believe we actually do understand the relative magnitude of factors contributing to pulmonary blood flow in the Fontan circulation. The primary driver is the engine-the cardiac output generated by the single ventricle, which will not be affected by FUEL. My experience with patients requiring surgical therapy for failing Fontans has been that in nearly all circumstances it is the engine that is the source of Fontan failure. $^{2}$ Medical manipulation of the pulmonary vascular resistance as demonstrated by the FUEL trial had a minimal effect. It is the pump, the single ventricle, the engine that is the primary driver of pulmonary blood flow. No matter how 